\title{
PESSOAS COM DEFICIÊNCIA E SEU DIREITO À INCLUSÃO NO MERCADO DE TRABALHO
}

\author{
PEOPLE WITH DISABILITIES AND THEIR RIGHT TO INCLUSION IN THE
} LABOR MARKET

\section{PERSONAS CON DISCAPACIDAD Y SUS DERECHOS DE INCLUSIÓN EN EL MERCADO DE TRABAJO}

\author{
HAMANDA DE NAZARÉ FREITAS MATOS \\ https://orcid.org/0000-0002-2233-797X / http://lattes.cnpq.br/6514099279014627 / hamandanfmatos@gmail.com \\ Universidade Federal do Pará \\ Belém, Pará, Brasil.
}

\author{
RAIMUNDO WILSON GAMA RAIOL \\ https://orcid.org/0000-0001-9388-3567 / http:/ / lattes.cnpq.br/6271053538285645 / rwraiol@gmail.com \\ Universidade Federal do Pará \\ Belém, Pará, Brasil.
}

\begin{abstract}
RESUMO
0 presente artigo científico tem como foco discutir as normas de acesso e de permanência das pessoas com deficiência no mercado de trabalho, bem como as dificuldades enfrentadas nesse processo. Tem-se uma legislação brasileira de inclusão muito avançada e que assegura com maestria os direitos das PCDs, de maneira que o problema da efetividade das normas não se dá exatamente por causa do trato jurisdicional. Dá-se, sim, devido ao aspecto comportamental das demais pessoas que, de alguma forma, se relacionam com as PCDs no ambiente de trabalho. Em razão disso, esta pesquisa se desenvolve a partir de uma análise bibliográfica, utilizando-se também de outros instrumentos, tais como dados estatísticos, elementos jurisprudenciais dos tribunais brasileiros e legislação nacional e internacional, com a intenção de descobrir como ultrapassar os obstáculos que impossibilitam ou, pelo menos, dificultam a implementação dessas regras, de forma que, ao menos, encontrem-se medidas alternativas que assegurem os direitos das PCDs ao ingresso e permanência no mercado de trabalho.
\end{abstract}

Palavras-chave: Inclusão social; Mercado de Trabalho; Pessoas com Necessidades Especiais.

\begin{abstract}
The present scientific article focuses on discussing the norms of access and permanency of people with disabilities in the job market, as well as the difficulties faced in this process. There is a very advanced Brazilian legislation of inclusion that ensures the rights of the PWDs with mastery, so that the problem of the effectiveness of the norms is not precisely connected to the jurisdictional treatment, but due to the behavioral aspect of the other people who, in some way, relate to PWDs in the workplace. As a result, a bibliographic research has been developed, using other instruments such as statistical data, jurisprudential elements of the Brazilian courts and national and international legislation. The intention is to find out how to overcome the obstacles that impede or, at least, hamper the implementation of these rules, so that, at least, alternative measures are in place to ensure the rights of PWDs to enter and remain in the job market.
\end{abstract}

Keywords: Social inclusion; Job market; People with disabilities. 


\section{RESUMEN}

El presente artículo científico tiene como foco discutir las normas de acceso y permanencia de las personas con discapacidad en el mercado de trabajo, así como las dificultades enfrentadas en este proceso. Hay en Brasil una normativa de inclusión muy avanzada y que asegura con aptitud los derechos de las PCDs, de manera que el problema de la efectividad de las normas no se debe exactamente por el tracto jurisdiccional, y sí debido al aspecto comportamental de las demás personas que, de alguna forma, se relacionan con las PCDs en ambiente de trabajo. En razón de eso, esta investigación se desarrolla a partir de un análisis bibliográfico, utilizando también de otros instrumentos, tales como dados estadísticos, elementos jurisprudenciales de los tribunales brasileños y la legislación nacional e internacional, con el intento de descubrir cómo superar los obstáculos que imposibilitan o, al menos, dificultan la implementación de tales reglas, de forma que, al menos, se encentren medidas alternativas que aseguren los derechos de las PCDs al ingreso y permanencia en lo mercado de trabajo.

Palabras-clave: Inclusión social; Mercado de Trabajo; Personas con Discapacidad.

\section{SUMÁRIO}

INTRODUÇAO; 1 EVOLUÇÃO LEGISLATIVA DOS DIREITOS TRABALHISTAS DAS PCDs; 2 EFETIVIDADE DAS NORMAS DE INCLUSÃO; 3 OBSTÁCULOS PARA A INSERÇÃO DE PESSOAS COM NECESSIDADES ESPECIAIS NO MERCADO DE TRABALHO; 3.1 Acessibilidade; 3.2 Violência Moral; 3.3 A "Falta de Pessoas Com Deficiência"; 4 MEIOS ALTERNATIVOS DE EFETIVAÇÃO DAS NORMAS REGULADORAS DA INSERÇÃO E PERMANÊNCIA DAS PESSOAS COM NECESSIDADES ESPECIAIS NO MERCADO DE TRABALHO; 4.1 Terminologias Utilizadas em Sistemas Inclusivos; 4.2 Propostas Alternativas de Inclusão; 4.3 Medidas alternativas tomadas em outros países; CONCLUSÃO; REFERÊNCIAS.

\section{INTRODUÇÃO}

A busca pela equidade entre pessoas com e sem deficiência no que diz respeito às oportunidades de acesso e permanência no mercado de trabalho encontra-se fundamentada na necessidade inerente ao indivíduo de alcançar sua autonomia e independência financeira, aliada ao sentimento de contribuição para o desenvolvimento econômico e social do país.

São consideradas pessoas com deficiência, no Brasil, aquelas que se singularizam por “impedimento de longo prazo de natureza física, mental, intelectual ou sensorial, o qual, em interação com uma ou mais barreiras, pode obstruir sua participação plena e efetiva na sociedade em igualdade de condições com as demais pessoas", nos moldes em que as conceitua o art. $1^{\circ}$ da Convenção Internacional sobre os Direitos das Pessoas com Deficiência e seu Protocolo Facultativo, oriunda da Organização das Nações Unidas (ONU) e promulgada, no Brasil, pelo Decreto Federal $n^{\circ} 6.949$, de 25 de agosto de 2009. ${ }^{1}$ Por sua vez, a Lei $n^{\circ} 13.146$, de 06 de

\footnotetext{
${ }^{1}$ BRASIL. Decreto $n^{\circ}$ 6.949, de 25 de agosto de 2009. Promulga a Convenção Internacional sobre os Direitos das Pessoas com Deficiência e seu Protocolo Facultativo, assinados em Nova York, em 30 de março de 2007. Diário Oficial da República Federativa do Brasil, Brasília, DF, 26. ago. 2009. Disponível em: <http://www.planalto.gov.br/ccivil_03/_ato2007-2010/2009/decreto/d6949.htm> Acesso em: 08 mar. 2017.
} 
julho de 2015, cognominada de Lei Brasileira de Inclusão da Pessoa com Deficiência ou Estatuto da Pessoa com Deficiência, adotou, em seu art. $2^{\circ}$, inteiramente aquele conceito. ${ }^{2}$

A compreensão que flui desse conceito é a de que não bastam as limitações físicocorporais, mentais, psíquicas, sensoriais, ou seja, auditivas ou visuais, pois essas suas singularidades devem estar em conjunto com barreiras diversas, existentes nas edificações, nos meios de transporte ou de comunicação, e também as representadas por preconceitos, estigmas e discriminações, para que as pessoas com deficiência sejam obstadas de participar da vida em sociedade tanto quanto as pessoas que não apresentem aquelas singularidades ou características. Como a concebe José Pastore,$^{3}$ a ideia de Pessoa com Deficiência está mais ligada ao aspecto social que às próprias limitações do indivíduo, de forma que, ao se proporcionar condições adequadas, determinada pessoa possa deixar de ser deficiente.

Juridicamente, no Brasil, a discussão a respeito dos direitos trabalhistas das pessoas com deficiência vem se dando amplamente desde o Programa de Ação a Curto, Médio e Longo prazo, lançado após a declaração do ano de 1981 como Ano Internacional das Pessoas Deficientes, pela Organização das Nações Unidas (ONU). Depois disso, muitos outros diplomas legais que tratam da questão surgiram, com abrangência nacional e internacional.

Ainda que a discussão a respeito dos direitos trabalhistas das PCDs seja relativamente atual, há uma pluralidade de normas de regulam o exercício de tais direitos e que promovem a inclusão, o que leva ao seguinte questionamento: qual o grau de efetividade destas normas hoje, considerando que o preconceito contra essas minorias continua latente na sociedade e a responsabilidade social com relação às pessoas com deficiência é bastante inferior ao mínimo necessário?

Utilizando-se dos métodos quantitativos e qualitativos de pesquisa, com suporte em metodologia bibliográfica, além de dados estatísticos do último censo oficial do Instituto Brasileiro de Geografia e Estatística (IBGE), realizado em 2010, e do levantamento das principais legislações, nacionais e internacionais referentes à inclusão e à permanência em igualdade de oportunidades com as demais pessoas no mercado de trabalho, traz-se à discussão o que se pode fazer para que as pessoas com deficiência tenham acesso a esse mercado ou permanência nele,

2 BRASIL. Lei $\mathrm{n}^{\circ}$ 13.146, de 6 de julho de 2015. Institui a Lei Brasileira de Inclusão da Pessoa com Deficiência (Estatuto da Pessoa com Deficiência). Diário Oficial da República Federativa do Brasil, Brasília, DF, 7. jul. 2015. Disponível em: <http://www.planalto.gov.br/ccivil_03/_ato20152018/2015/lei/l13146.htm>. Acesso em: 09. mar. 2017.

3 PASTORE, José. Oportunidades de trabalho para portadores de deficiência. São Paulo: Editora LTr, 2000. p. 15. 
de maneira que se sintam incluídas de fato e que essa inclusão não envolva apenas o acesso à vaga de trabalho, mas também a participação efetiva nas tarefas comuns no ambiente laboral.

Para isso, será discutida a efetividade das normas assecuratórias dos direitos trabalhistas das pessoas com necessidades especiais, os principais obstáculos que as PCDs enfrentam diariamente, além das medidas alternativas que possam eliminar esses obstáculos de forma efetiva.

\section{EVOLUÇÃO LEGISLATIVA DOS DIREITOS TRABALHISTAS DAS PCDS}

Antes de se discorrer sobre a aplicação da norma nos casos concretos, faz-se necessária uma análise do ordenamento jurídico nacional e internacional, a fim de compreender como se deu a evolução legal das garantias dos direitos das pessoas com deficiência à inclusão no mercado de trabalho, destacando as principais conquistas.

A Organização das Nações Unidas (ONU) declarou o ano de 1981 como sendo o Ano Internacional das Pessoas Deficientes. O resultado mais importante daquela declaração, para o Brasil, foi o Programa de Ação a Curto, Médio e Longo Prazo, relativo às pessoas com deficiência, o qual, dentre os seus objetivos, incluía-se a capacitação profissional e acesso da pessoa com deficiência ao trabalho.

Marta Gil chama atenção para a relevância da participação do Brasil como país membro da ONU, tendo em vista que, nesse contexto, houve um fortalecimento do movimento das pessoas com deficiência que estavam em busca de protagonismo de sua própria história, o que acabou coincidindo com o processo de redemocratização do Brasil, próximo à edição da Carta Magna de $1988 .{ }^{4}$

Em 1982, o Programa de Ação Mundial para as Pessoas com Deficiência foi aprovado pela Assembleia Geral das Nações Unidas, em seu trigésimo sétimo período de sessões, pela Resolução 37/52, de 03 de dezembro de 1982. O programa lança propostas e faz denúncias, como a de que, na época, o número real de pessoas com deficiência empregadas em estabelecimentos comuns ou especiais estaria muito abaixo daquele correspondente ao número de pessoas com deficiência capazes de trabalhar, o que significa que o problema para inserção dessas pessoas seria não só de adaptação ao trabalho em si, mas também da discriminação decorrente do preconceito por parte das empresas contratantes.

\footnotetext{
${ }^{4}$ GIL, Marta. Caminhos da Inclusão: a história da formação profissional de pessoas com deficiência no SENAI/SP. São Paulo: SENAI-SP Editora, 2012. p. 248.
} 
No âmbito do ordenamento jurídico brasileiro, a defesa de direitos ao trabalho só foi suscitada com o advento da Constituição Federal de $1998,{ }^{5}$ sendo materializada no seu art. $7^{\circ}$, que proíbe qualquer discriminação referente ao salário e critérios de admissão do trabalhador que é pessoa com deficiência.

Nesse dispositivo, fora assegurado objetivamente o direito à pessoa com deficiência de receber um salário justo e igual ao de qualquer outro trabalhador que exerça funções iguais. Ainda não havia sido explorado, no ordenamento jurídico brasileiro, o direito ao trabalho das pessoas com deficiência, por isso que se pode considerar esse dispositivo constitucional como um marco na história dos direitos trabalhistas das PCDs no Brasil.

Um ano após a promulgação da atual Constituição Federal, a Lei $n^{\circ} 7.853$, de 24 de outubro de $1989,{ }^{6}$ em seu art. $8^{\circ}$, incisos II e III, tipificou como crime, punível com reclusão de 2 (dois) a 5 (cinco) anos e multa, a oposição à inscrição de candidato a concurso público, pelo fato de o interessado apresentar deficiência, bem com negar-lhe emprego ou promoção, em decorrência do mesmo motivo.

Por sua vez, o diploma que dispõe sobre o regime jurídico dos servidores públicos, ou seja, a Lei $n^{\circ} 8.112$, de 11 de dezembro de $1990,{ }^{7}$ além de reafirmar o direito das pessoas com deficiência ao acesso a cargos públicos, prevê, no art. $5^{\circ} \S 2^{\circ}$, a reserva de até $20 \%$ (vinte por cento) das vagas oferecidas em concurso público, trazendo a ideia de justiça segundo a qual a disputa de vagas se daria em igualdade de condições. Acoplando-se a essa previsão legal, o Decreto $n^{\circ} 9.508$, de 24 de setembro de 2018 , estipula, no art. $1^{\text {a }}$, $\S 1^{\circ}$, que deve ser ofertado o mínimo de $5 \%$ de vagas em concursos para provimento de cargos públicos efetivos, bem como, como novidade legislativa, "para a contratação por tempo determinado para atender necessidades temporária de excepcional interesse púbico", com vistas a atuarem no âmbito da

\footnotetext{
${ }^{5}$ BRASIL. Constituição Federal. Diário Oficial da União. Brasília: Senado Federal, 1988. Disponível em: <http://www.planalto.gov.br/ccivil_03/Constituicao/Constituiçao.htm>. Acesso em: 12 de dez. 2016

6 BRASIL. Lei $n^{\circ} 7.853$, de 24 de outubro de 1989. Dispõe sobre o apoio às pessoas portadoras de deficiência, sua integração social, sobre a Coordenadoria Nacional para Integração da Pessoa Portadora de Deficiência - Corde, institui a tutela jurisdicional de interesses coletivos ou difusos dessas pessoas, disciplina a atuação do Ministério Público, define crimes, e dá outras providências. Diário Oficial da República Federativa do Brasil, Brasília, DF, 25. out. 1989. Disponível em: <http://www.planalto.gov.br/ccivil_03/Leis/L7853.htm> Acesso em: 07 mar. 2018.

7 BRASIL. Lei $n^{\circ} 8.112$, de 11 de dezembro de 1990. Dispõe sobre o regime jurídico dos servidores públicos civis da União, das autarquias e das fundações públicas federais. Diário Oficial da República Federativa do Brasil, Brasília, DF, 19. abr. 1991. Disponível em: <http://www.planalto.gov.br/ccivil_03/Leis/L8112cons.htm>. Acesso em: 07 mar. 2017.
} 
administração pública federal direta e indireta. ${ }^{8}$ Anteriormente, o referido percentual estava assegurado a pessoas com deficiência pretendentes de ocupação de cargos públicos efetivos, por força do art. 37, § 1, do Decreto $n^{\circ}$ 3.298, de 20 de dezembro de 1999, dispositivo revogado por aquele decreto, em plena vigência. ${ }^{9}$

Conquistado o direito à reserva de vagas em cargos públicos, o próximo passo se deu com a importantíssima e polêmica Lei $n^{\circ}$ 8.213, de 24 de julho de 1991, a Lei de Cotas, que no seu art. 93, declara que é obrigada a empresa com mais de 100 empregados a reservar entre $2 \%$ a $5 \%$ das vagas de empregos aos beneficiários reabilitados ou pessoas com deficiência. Tal percentual está previsto no art. 36 do Decreto $\mathrm{n}^{\circ} 3.298$, de 20 de dezembro de $1999 .^{10}$

Por determinação do novel Decreto $\mathrm{n}^{\circ}$ 9.508, de 24 de setembro de 2018, como estabelece o seu art. $1^{\circ}$, o sistema de cotas em referência será aplicado, também, às empresas públicas e às sociedades de economia mista. Constitui-se essa previsão normativa uma ampliação em prol das pessoas com deficiência.

Em 1993, foram editadas as Normas de Equiparação de Oportunidades para Pessoas com Deficiência, pela ONU, que foram adotadas pela Assembleia Geral das Nações Unidas na sua Resolução $n^{\circ}$ 48/96, que, na regra 7 , dispõe sobre emprego e atribui ao Estado o dever de igualar as oportunidades de acesso ao mercado de trabalho em prol das pessoas com deficiência, seja na zona urbana seja rural, de modo a conseguirem emprego produtivo e remunerado.

\footnotetext{
${ }^{8}$ BRASIL. Decreto $n^{\circ} 9.508$, de 24 de setembro de 2018. Reserva às pessoas com deficiência percentual de cargos e de emprego públics ofertados em concursos públicos e em processos seletivos no âmbito da administração públca federal direta e indireta. Diário Oficial da República Federativa do Brasil, Brasília, DF, 25. set. 2018. Disponível em: http://www.planalto.gov.br/ccivil_03/_ato20072010/2009/decreto/d9508.htm Acesso em: 27 set. 2018.

9 BRASIL. Decreto $n^{\circ} 3.298$, de 20 de dezembro de 1999. Regulamenta a Lei no 7.853 , de 24 de outubro de 1989, dispõe sobre a Política Nacional para a Integração da Pessoa Portadora de Deficiência, consolida as normas de proteção, e dá outras providências. Diário Oficial da República Federativa do Brasil, Brasília, DF, 21. dez. 1999. Disponível em: < http://www.planalto.gov.br/ccivil_03/decreto/d3298.htm Acesso em: 08 mar. 2017.

${ }^{10}$ BRASIL. Lei $n^{\circ}$ 8.213, de 24 de julho de 1991. Dispõe sobre os Planos de Benefícios da Previdência Social e dá outras providências. Diário Oficial da República Federativa do Brasil, Brasília, DF, 25. jul. 1991, republicado 11. abr. 1996 e republicado em 14. ago. 1998. Disponível em: <http://www.planalto.gov.br/Ccivil_03/leis/L8213cons.htm>. Acesso em: 09. mar. 2017. Art. 93. A empresa com 100 (cem) ou mais empregados está obrigada a preencher de $2 \%$ (dois por cento) a $5 \%$ (cinco por cento) dos seus cargos com beneficiários reabilitados ou pessoas portadoras de deficiência, habilitadas, na seguinte proporção:

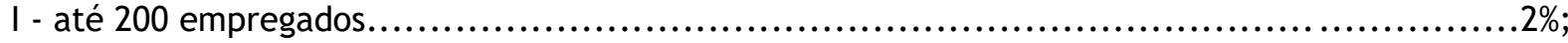

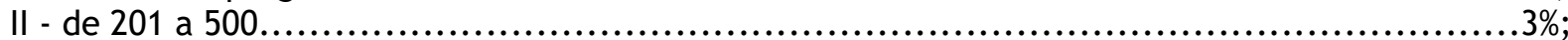

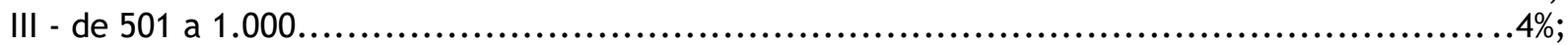

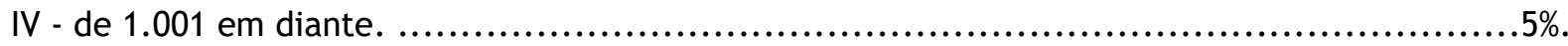


No item 2 dessa mesma regra, são elencados diversos mecanismos de que o Estado pode utilizar para dar apoio a essas pessoas, constando dentre eles a formação vocacional, esquemas de quotas baseados em incentivos, emprego protegido, contratos de exclusividade ou direitos de produção prioritários, isenções fiscais, supervisão contratual ou outra forma de assistência técnica e financeira às empresas que empregarem trabalhadores com deficiências etc. No item 3, que alude aos programas de ação dos Estados, são mencionadas a acessibilidade nos locais de trabalho e utilização de novas tecnologias para que as pessoas com deficiência possam realizar suas atividades da melhor forma possível, tenham seus limites superados e possam obter e conservar seus empregos.

Em 2009, houve, por meio do Decreto $\mathrm{n}^{\circ}$ 6.949, de 25 de agosto, a promulgação da Convenção Internacional sobre os Direitos das Pessoas com Deficiência e seu Protocolo Facultativo, antes aprovados pela ONU, que vem servindo de fundamento para grande parte das decisões dos tribunais brasileiros relativas aos direitos das PCDs. No art. 27, que trata do trabalho e emprego, é atribuído aos Estados Partes o dever de reconhecer às pessoas com deficiência o direito ao trabalho em igualdade de oportunidades e condições tanto quanto às demais pessoas, bem como manter-se no seu trabalho, em ambiente aberto, acessível e com a total liberdade de exercer seus direitos trabalhistas e sindicais. É assegurado também que as pessoas com deficiência não serão mantidas em escravidão ou servidão bem como no trabalho forçado.

Recentemente, no ano de 2015, foi dado mais um enorme salto na legislação nacional com a promulgação da Lei $n^{\circ} 13.146$, de 06 de julho de 2015, denominada de Lei Brasileira de Inclusão ou Estatuto da Pessoa com Deficiência. Essa lei incumbiu não somente ao Estado, mas também à sociedade e à família o dever de assegurar e incentivar às PCDs, dentre outros direitos, o pertinente ao trabalho, consoante seu art. $8^{\circ} .0$ art. $34, \S 1^{\circ}$, da referida lei afirma, categoricamente, que as pessoas jurídicas de direito público e privado ou de qualquer natureza estão obrigadas a garantir ambientes de trabalho acessiveis e inclusivos.

0 art. 37 da predita lei elenca diversas formas mediante as quais caracteriza os modos de inclusão da pessoa com deficiência, dentre eles, a colocação competitiva, no mercado, em igualdade de oportunidades com as demais pessoas, sendo atendidas as regras de acessibilidade e a adaptação razoável do ambiente de trabalho. 


\section{EFETIVIDADE DAS NORMAS DE INCLUSÃO}

A Lei de Cotas, bem como as demais leis (sentido amplo) mencionadas possuem um grande problema quanto à sua implementação. Na triste realidade em que se vive no Brasil, infelizmente a maioria dos empregadores que contratam PCDs obedece à norma unicamente como forma de se manter nos padrões legais, conforme se depreende da pesquisa realizada pela Associação Brasileira de Recursos Humanos (ABRH) Nacional Isocial e Catho, que entrevistou cerca de 2.949 (dois mil, novecentos e quarenta e nove) profissionais do setor, em 2014. Como resultado, foi apontado que $81 \%$ (oitenta e um por cento) dos recrutadores contratam pessoas com deficiência, tendo como objetivo único o de “cumprir a lei”. Apenas 4\% (quatro por cento) dos entrevistados afirmou contratar por "acreditar no potencial", 12\% (doze por cento) o fazem "independente de cota" e 3\% (três por cento) porque "valorizam a diversidade". ${ }^{11}$

Analisando tais estimativas, percebe-se que ainda há muito receio em contratar pessoas com necessidades especiais, vez que, no geral, estas acabam não sendo vistas pelo empregador como capazes de exercer funções de forma qualificada e que contribua para o progresso dos negócios. São tidas como um problema a ser carregado pela empresa, que as deve incluir no seu quadro de pessoal somente porque a lei assim ordena, sob pena de sanção. Tal conduta vai totalmente contra o objetivo das leis inclusivas, assim como fere de morte o princípio constitucional da dignidade humana, que é direito fundamental por excelência.

Ainda utilizando os dados da pesquisa realizada pela $\mathrm{ABRH}$, solicitou-se ao $\mathrm{RH}$ indicasse quais seriam as três maiores barreiras para a inserção das PCDs no mercado de trabalho. Apurouse que a acessibilidade fora indicada pela maioria como a maior delas, seguida pelo foco exclusivo no cumprimento de cotas e falta de preparo dos gestores. Isso reflete a falta de compromisso dessas empresas para com os empregados que padecem de deficiências.

A fim de visualizar o dever da empresa em proporcionar todo o aparato à $P C D$, de modo a que possibilite a sua acessibilidade, avalie-se algumas palavras do relator desembargador Luiz Otavio Linhares Renault, no julgamento de recurso ordinário, no Tribunal Regional do Trabalho da $3^{\text {a }}$ Região, ao justificar seu voto:

11 Dados coletados em 2014 pela ABRH Nacional, Isocial e Catho. 
[...] as empresas necessitam se adequar às dificuldades que as pessoas portadoras de deficiências detêm. Dessa forma, não há como exigir dos aludidos deficientes os mesmos requisitos para a admissão de um empregado comum. A Lei [de cotas] tem como escopo a inserção no mercado de trabalho, de pessoas excluídas e até marginalizadas, sem nenhuma perspectiva de avanço profissional. E a empresa, como parte de sua função social, tem obrigação de ajudar, seja adaptando-se física ou "mentalmente" para receber os aludidos profissionais. ${ }^{12}$

Assim, deve-se estar ciente de que o local de trabalho é que precisa se adequar às limitações da pessoa com deficiência que naquele ambiente labuta, não o inverso. Quanto ao voto do desembargador, este, ao pontuar que a empresa deverá se adaptar "física ou ‘mentalmente' para receber os aludidos profissionais”, está se referindo tanto ao espaço físico onde o trabalhador pessoa com deficiência irá exercer suas funções, como à preparação psicológica dos demais empregados, para que haja uma harmoniosa convivência com o colega que possui necessidades especiais.

Outro fato pertinente é o direito do empregado PCD a manter-se em seu cargo, podendo o empregador dispensá-lo, nos termos do art. 93, \$1, da Lei n 8.213/91 (Lei de Cotas), somente após a contratação de outro trabalhador com deficiência.

Destaca-se que a lei não confere ao empregado, enquanto pessoa com deficiência, nenhum tipo de estabilidade, apenas garante que as cotas sejam preenchidas conforme os parâmetros apontados na própria lei. No entanto, é entendimento pacificado na jurisprudência que a finalidade da cota é a busca pela inclusão desses profissionais no mercado de trabalho, de forma que não é o simples acesso à vaga que caracteriza o viés inclusivo, e, sim, a participação de fato de pessoas com necessidades especiais nas atividades que o cargo requer. Assim, o empregador só poderá dispensar uma PCD quando contratar outra, para que a finalidade da lei seja cumprida.

\footnotetext{
12 BRASIL. Tribunal Regional do Trabalho da $3^{\text {a }}$ Região. Acórdão de decisão que deu provimento parcial para condenar a primeira ré ao pagamento de indenização por dano moral. Recurso Ordinário $\mathrm{n}^{\circ} 00611$ 2007-021-03-00-7. Ministério Público Do Trabalho. Relator: Luiz Otávio Linhares Renault. 04 de junho de 2008. Disponível em: <https://trt-3.jusbrasil.com.br/jurisprudencia/129544493/recurso-ordinariotrabalhista-ro-611200702103007-0061100-4020075030021 >. Acesso em: 19 mar. 2017
} 


\section{OBSTÁCULOS PARA A INSERÇÃO DE PESSOAS COM NECESSIDADES ESPECIAIS NO MERCADO DE TRABALHO}

$\mathrm{Na}$ constante busca pela inclusão, muitos obstáculos podem acabar surgindo, de modo que se faz necessário conhecer até que ponto podem interferir na vida profissional das pessoas com deficiência. A análise sobre acessibilidade, violência moral e a "falta de pessoas com deficiência" talvez sejam o ponto de partida para que se possa compreender o porquê das PCDs serem tão "invisíveis" no mundo das relações de trabalho.

\subsection{Acessibilidade}

A falta de acessibilidade é o primeiro obstáculo a ser enfrentado na busca pela inclusão das PCDs. Após a análise dos posicionamentos que diversos doutrinadores têm a respeito da acessibilidade, pode-se afirmar que este é um triplo obstáculo, visto que o problema quanto ao acesso pode se dar pelo lugar, espaço e/ou acesso físico.

A acessibilidade quanto ao lugar diz respeito ao acesso ao cargo desejado pela PCD, sendo esse lugar caracterizado como o local onde as atividades econômicas serão praticadas. 0 dispositivo legal que prevê esse tipo de acesso é a Lei $8.112 / 90$, que, no art. $5^{\circ} \S 2^{\circ}$, estabelece a reserva de vagas para concursos públicos para pessoas com deficiência.

Contudo, a acessibilidade não diz respeito apenas ao acesso ao lugar, mas também à possibilidade de criação e recriação de um espaço, como apontam Carvalho-Freitas e Marques $(2010 \text {, p. 117 })^{13}$. É o que se denomina de acessibilidade quanto ao espaço, que compreende tudo com o que o indivíduo se relaciona no ambiente coletivo de trabalho, sejam os colegas, sejam as atividades ali produzidas. Computadores adaptados para deficientes visuais, elevadores, inclusive com voz digitalizada e botoeiras em braile, banheiros adaptados, mesas com encaixe para cadeira de rodas, enfim, adaptações de qualquer natureza com a finalidade de que haja maior conforto e rendimento do funcionário, são formas de acessibilidade quanto ao espaço.

A recente Lei $n^{\circ} 13.146 / 2015$, Lei Brasileira de Inclusão, no seu Capítulo VI, obriga as pessoas jurídicas de direito público e privado a garantirem ambientes de trabalho acessíveis e

13 FREIRE VAZ, Cláudia. LIMA, Gabriela Silva de. BEZERRA, Priscila Silva. BRAGA, Maudeth Py. Acessibilidade: da obtenção de um lugar à construção de um espaço. In: CARVALHO-FREITAS, Maria Nivalda de. MARQUES, Antônio Luiz. Trabalho e Pessoas com deficiência: Pesquisas, Práticas e Instrumentos de Diagnóstico. [Local]:[Editora], 2010. p. 173 
inclusivos, materializando, desse modo, a ideia de acessibilidade quanto ao espaço. Dessa forma, todos os mecanismos de acessibilidade possíveis deverão ser utilizados em favor da pessoa com deficiência, a fim de que, em prol desta, haja a manutenção em seu cargo e os obstáculos vencíveis não se tornem reais barreiras à sua inserção no mercado de trabalho.

Quanto ao acesso físico, há um enorme problema enfrentado pelas PCDs diariamente: a dificuldade em chegar ao trabalho. Essa problemática pode se dar "tanto pela dificuldade financeira em comprar automóvel adaptado, como pela inadequação dos meios de transporte urbano que não estão adaptados para transportar com segurança e conforto pessoas com deficiência"14. Ademais, quando o transporte coletivo é adaptado, há casos em que os motoristas não param os ônibus fingindo não ver o cidadão sinalizando, na parada de ônibus.

\subsection{Violência Moral}

O homem, no cenário econômico atual, é visto como mero número que está ali, à inteira disposição do mercado, para produzir, usando a sua força de trabalho. Assim os trabalhadores deixam de ser vistos como pessoas dignas e o ambiente laboral acaba se tornando local propício para o desenvolvimento de violência moral, práticas de humilhação e/ou de constrangimento. Sabe-se que grupos vulneráveis tais como os das pessoas com deficiência são mais propícios a se tornarem alvos de práticas de constrangimento e de humilhação, no ambiente de trabalho, o que torna ainda mais difícil a inclusão social das referidas pessoas.

Muitas pessoas, ao procurar emprego, devem ter se deparado com empresas contratantes fazendo as seguintes exigências: "procuramos pessoas jovens" e "de boa aparência", tendo, assim, a estética como requisito essencial para contratação. Muitas vezes, como afirmam Siqueira e Simões ${ }^{15}$, "boa aparência, boa dentição, não afeminado, jovem, dentre outras características (...) se sobressaem frente às próprias capacidades, conhecimentos e habilidades do candidato". Dessa forma, observa-se que essa é provavelmente mais uma das causas para não contratação das pessoas com deficiência. A busca por uma boa aparência acaba representando

\footnotetext{
${ }^{14}$ SIQUEIRA, Marcus Vinicius Soares; SIMÕES, Jussara Tatiana de Oliveira. Violência Moral e Pessoas com Deficiência: Constrangimentos e Humilhações no Ambiente de Trabalho. Belo Horizonte: V Encontro de Estudos Organizacionais da ANPAD, 2008, p. 9.

${ }^{15}$ SIQUEIRA, Marcus Vinicius Soares; SIMÕES, Jussara Tatiana de Oliveira. Violência Moral e Pessoas com Deficiência: Constrangimentos e Humilhações no Ambiente de Trabalho. Belo Horizonte: V Encontro de Estudos Organizacionais da ANPAD, 2008, p. 2
} 
um caráter decisivo nesses processos seletivos e a pessoa com deficiência, embora, muitas vezes, com boa qualificação, acaba perdendo a vaga, por apresentar suas peculiaridades.

Deve-se deixar claro também que a violência moral pode se manifestar de duas formas. Uma delas é a mencionada, por meio de humilhações e constrangimentos, ou pelo mero desprezo, mediante discriminação. Essa falta de apreço para com o colega que é pessoa com deficiência, somada à falta de acessibilidade, pode tornar o trabalhador com essa singularidade cada vez mais frustrado e impotente, fazendo-o desanimar-se de seu emprego.

A pessoa com deficiência, assim, acaba perdendo sua própria identidade, dentro do ambiente de trabalho, visto que muitas delas deixam de ser identificadas pelo seu nome e passam a ser chamadas por termos pejorativos por parte dos colegas de trabalho e são tratadas com inferioridade. Além disso, várias empresas contratam pessoas com deficiência apenas para o cumprimento da cota, depois dispensam os seus serviços e pedem para que o trabalhador fique em casa. ${ }^{16}$

A diferença de tratamento com relação ao empregado PCD e aos demais empregados é uma afronta direta à norma constitucional citada no trecho da decisão. Além do mais, tal discriminação afeta diretamente o ego do empregado com deficiência, causando dor e humilhação, cabendo até mesmo responsabilização civil por dano moral, o que condiz com os artigos 186 e 187 do Código Civil Brasileiro.

\subsection{A "Falta de Pessoas Com Deficiência"}

A falta de pessoas com deficiência é um obstáculo alegado pelas empresas. À primeira vista, a afirmação de que as empresas têm dificuldade em contratar pessoas com deficiência devido ao número insuficiente de trabalhadores em tais condições, soa no mínimo estranho, visto que, no último censo oficial realizado pelo IBGE foi constatado que aproximadamente 45 milhões de brasileiros, quase $24 \%$ da população, apresentam-se com algum tipo de deficiência ${ }^{17}$.

Sendo assim, o que fundamentaria os inúmeros pedidos de dispensa de obrigação das empresas em preencher as vagas destinadas às PCDs, exigidas pela Lei de Cotas, junto aos tribunais do trabalho? A resposta para a essa pergunta é relativamente simples, conforme se demonstrará.

\footnotetext{
16 Siqueira e Prelorentzou chegaram a essas informações após uma entrevista realizada com diversas pessoas com deficiência no Distrito Federal.

17 Dados recolhidos com base no censo de 2010.
} 
O reduzido número se dá visto que grande parte das pessoas com deficiência não podem ser computadas como estando disponíveis para a inserção ao mercado de trabalho por meio da cota. Manica e Caliaman ${ }^{18}$ enumeram cinco motivos que impedem o empresário de contratar as pessoas com deficiência, a fim de cumprir a cota legal. 0 primeiro deles seria a diferença de graus e tipos de deficiência, situação em que, geralmente, são computadas as de maior grau de comprometimento e podem ser encontradas na classificação expressa do Decreto $n^{\circ} 5.296$, de 2 de dezembro de 2004.

O segundo motivo seria o de que no rol dessas 45 milhões de pessoas, também, estão incluídas as pessoas aposentadas e que não poderão mais se juntar à população economicamente ativa. Nesta mesma linha se situam as crianças (terceiro motivo), que também estão dentre os 45 milhões, mas não podem trabalhar, pois ainda não possuem a idade mínima necessária, para isso.

0 quarto motivo estaria relacionado às pessoas que recebem o benefício de um salário mínimo do Estado, o BPC (Beneficio de Prestação Continuada), que, por algum motivo, não desejam inserir-se no mercado ou têm medo de perder o montante que é a complementação da renda familiar.

Além desses, os autores citam como o quinto motivo a falta de instrução, pois, para que a empresa possa contratar, é exigido certo nível de escolaridade de acordo com a atividade a ser desempenhada. Mesmo com políticas de inclusão adotadas pelo governo, a baixa escolaridade das pessoas com deficiência é muito grande, devido a fatores como a falta de escolas adaptadas para alunos com necessidades especiais. Dados recolhidos pelo MEC, em 2013 mostram que 30 mil PCDs se matricularam na graduação, frente aos quase 7,3 milhões demais estudantes que também se matricularam em instituições do ensino superior. ${ }^{19}$ A propósito, acentua Marta Gil: "Uma das razões que as empresas industriais alegam - talvez a mais frequentemente utilizada, desde que a 'lei de cotas' foi regulamentada - para a não contratação de trabalhadores com deficiência é a sua falta de qualificação profissional". ${ }^{20}$

No entanto, a simples alegação desses motivos não basta para alguém escusar-se de cumprir com a obrigação de contratar pessoas com necessidades especiais e o descumprimento

18 MANICA, Loni Elisete; CALIMAN, Geraldo. Inclusão das pessoas com deficiência na educação profissional e no trabalho. 1. ed. Jundiaí: Paco Editorial.2015, p. 126-127.

${ }^{19}$ Fonte: Censo do Ministério da Educação (MEC) sobre dados de 2013.

${ }^{20} \mathrm{GIL}$, Marta. Caminhos da Inclusão: a história da formação profissional de pessoas com deficiência no SENAI/SP. São Paulo: SENAI-SP Editora, 2012.p.160. 
dessa obrigação poderá gerar o dever de indenização por dano moral coletivo decorrente de conduta omissiva.

\section{MEIOS ALTERNATIVOS DE EFETIVAÇÃO DAS NORMAS REGULADORAS DA INSERÇÃO E PERMANÊNCIA DAS PESSOAS COM NECESSIDADES ESPECIAIS NO MERCADO DE TRABALHO}

O conhecimento de medidas que possibilitem a acessibilidade, além das já mencionadas em norma positivada, abre uma maior gama de elementos que levam à efetividade das próprias normas. No rol desses elementos está o entendimento de terminologias como "acessibilidade total”, “desenho universal”, “tecnologias assistivas” e "comportamentos inclusivos", a fim de se expandir a compreensão acerca da acessibilidade, inclusão e direitos humanos das PCDs, e com o intuito de que o uso da tecnologia, por exemplo, auxilie e possibilite que a PCD possa exercer seus ofícios no local de trabalho com dignidade e conforto.

Além do conhecimento das terminologias, a doutrina cita outros meios que seguem com a participação das empresas contratantes, do Estado e outras parcerias, tendo em vista a conscientização dos que trabalham juntamente à PCD e a criação de ações afirmativas, quando necessário. No direito comparado têm-se como exemplo as medidas tomadas nos EUA, Itália e Espanha, países com interessantes políticas de inclusão das pessoas com necessidades especiais no mercado de trabalho.

\subsection{Terminologias utilizadas em Sistemas Inclusivos}

Inicialmente, para que haja a inserção e permanência das PCDs, Carvalho-Freitas e Marques $^{21}$ apontam que se faz necessário o entendimento dos conceitos de "acessibilidade total”, “desenho universal”, "tecnologias assistivas" e "comportamentos inclusivos".

A ideia de acessibilidade total nos remete aos conceitos de acessibilidade quanto ao lugar, espaço e acesso físico, mencionados no item 3.1 deste artigo. Dessa forma, a acessibilidade não se trata apenas da liberdade de locomoção, mas também o direito ao livre

${ }^{21}$ BAHIA, Melissa Santos. DOS SANTOS, Ernani Marques. Práticas empresariais para a inclusão profissional de pessoas com deficiência. In: CARVALHO-FREITAS, Maria Nivalda de; MARQUES, Antônio Luiz (Organizadores). Trabalho e pessoas com deficiência: Pesquisas, Práticas e Instrumentos de Diagnóstico. Curitiba: Juruá, 2010. p. 147. 
acesso aos bens, serviços e ambientes, sem qualquer obstáculo que o impeça de exercer seus direitos e ofícios no seu local de trabalho.

Um segundo conceito é o de desenho universal. Durante a Conferência Internacional sobre o Desenho Universal "Projetando para o século XXI", ocorrida, no Rio de Janeiro, em 12 de dezembro de 2004, foi declarado e concebido, na Carta do Rio, o desenho universal como sendo “um gerador de ambientes, serviços, programas e tecnologias acessíveis, utilizáveis equitativamente, de forma segura por todas as pessoas- na maior extensão possível- sem que tenham que ser adaptados ou readaptados especificamente". 0 objetivo do desenho industrial, afirmado na carta, é de incluir a maior quantidade de pessoas, inclusive as que têm dificuldade em interagir na sociedade e para seu desenvolvimento. Neste ponto se encontra o grupo das Pessoas com Deficiência.

As tecnologias assistivas são a área do conhecimento que propicia a valorização, integração e inclusão das pessoas com deficiência, de modo a promover os Direitos Humanos, fazendo-se necessário, para isso, a utilização de recursos e outros elementos para que se possa vencer obstáculos e barreiras para o alcance da acessibilidade. ${ }^{22}$

A respeito de comportamentos inclusivos, segundo a obra de Carvalho-Freitas e Marques, ${ }^{23}$ são "atitudes empreendidas para a convivência saudável e tranquila com as PCD, não só no ambiente de trabalho, mas em todos os ambientes". Os comportamentos inclusivos são muito importantes inclusive ao profissional com deficiência que está em processo de reabilitação. Paulo Antônio de Paiva Rebelo ${ }^{24}$ diz que "os colegas de trabalho devem ser orientados em relação aos cuidados a serem observados e regras de convívio social com as pessoas com deficiência, para criar a ambiência propícia ao acolhimento do colega e, se indicado, receberem também eles apoio psicológico".

Todos esses conceitos trazem em seu âmago como finalidade a inclusão. Seja com o auxílio da tecnologia ou com o afeto dos colegas de trabalho, o importante é que a pessoa com deficiência se sinta pertencente e tenha toda a liberdade de atuação no seu espaço de trabalho.

\footnotetext{
22 Brasil. Subsecretaria de Promoção dos Direitos da Pessoa com Deficiência. Comitê de Ajudas Técnicas. Tecnologia Assistiva. Brasília: CORDE, 2009. p. 138.

${ }^{23}$ CARVALHO-FREITAS, Maria Nivalda de; MARQUES, Antônio Luiz (Organizadores). Trabalho e pessoas com deficiência: Pesquisas, Práticas e Instrumentos de Diagnóstico. Curitiba: Juruá, 2010, p. 147.

${ }^{24}$ REBELO, Paulo Antônio de Paiva. A pessoa com deficiência e o trabalho. Rio de Janeiro: Qualitymark, 2008, p. 63.
} 


\subsection{Propostas Alternativas De Inclusão}

Manica e Caliman ${ }^{25}$ propõem que, para facilitar a empregabilidade das pessoas com deficiência, sugere-se que o Governo Federal e o Sistema "S"26 criem políticas de sensibilização aos empresários a respeito do potencial que têm as pessoas com deficiência, desmistificando a ideia de que estas atrasam a produtividade das empresas e explicando sobre os reais benefícios em se contratar PCDs. Deverão também ser feitas campanhas nas mídias em favor destas empresas que cumprem a cota, como forma de incentivar as outras a fazerem o mesmo.

Os doutrinadores sugerem também a criação de uma espécie de selo inclusivo que incentivaria as empresas a buscarem atender às demandas acima da cota prevista em Lei, bem como o Estado deveria criar temporariamente medidas compensatórias às empresas que cumprirem a Lei de Cotas, por exemplo concedendo-lhes benefícios fiscais.

Outra sugestão relevante é a de as empresas contratantes de pessoas com deficiência investirem na preparação de profissionais que, como já analisado nos resultados das pesquisas da $\mathrm{ABRH}$, supram a falta de preparo dos gestores. Essa falta representa um grande obstáculo que precisa ser superado, pois apenas profissionais qualificados saberão conduzir corretamente o processo de inclusão desse grupo humano vulnerável na empresa. A esses profissionais caberia também selecionar PCDs levando em consideração os diversos tipos de deficiência e seus diferentes graus.

Os autores sugerem, também, para que haja o cumprimento efetivo da norma, seja feita a revisão da legislação pelo Governo Federal, com o escopo de se realizarem concursos públicos para fiscais do trabalho, que poderão acompanhar a rotina e ver se as normas jurídicas de inclusão estão sendo aplicadas. Atualmente, essa função fiscalizatória cabe ao Ministério Público do Trabalho, no entanto, a criação de um cargo especial poderia trazer uma eficiência ainda maior, bem como diminuiria as demandas do MPT, que já possui tantas outras tarefas.

Sem embargo disso, o Governo Federal, ainda, em especial os institutos federais, bem como o sistema " $\mathrm{S}$ ", deverão buscar parcerias que possibilitem a capacitação profissional a fim de que haja a efetiva inclusão da PCD no mercado de trabalho. É sugerido, por fim, que as

\footnotetext{
25 MANICA, Loni Elisete; CALIMAN, Geraldo. Inclusão das pessoas com deficiência na educação profissional e no trabalho. 1. ed. Jundiaí: Paco Editorial. 2015, p. 175.

26 Sistema "S" "É formado pelo conjunto de organizações das entidades cooperativas voltadas para o treinamento profissional, assistência social, consultoria, pesquisa e assistência técnica, que além de terem seu nome iniciado com a letra ' $\mathrm{S}$ ', têm raízes comuns e características organizacionais similares". (Portal Brasil. Disponível em: <www.brasil.gov.br/educacao/2012/02/sistema-s-e-estrutura-educacionalmantida-pela-industria>. Acesso: 24 de abr. de 2017)
} 
escolas profissionalizantes disponibilizem livros e filmes com depoimento e casos de sucesso de inclusão de PCDs na empresa, para serem compartilhados entre os funcionários.

\subsection{Medidas alternativas tomadas em outros países}

Além das medidas sugeridas pelos doutrinadores apresentados, pode-se tomar também como alternativas as ações afirmativas praticadas por outros países que possuem políticas consistentes de inclusão das pessoas com deficiência, como os Estados Unidos, Itália e Espanha.

Nos EUA, é adotado o sistema de redução e de incentivos fiscais para a contratação de pessoas com deficiência, onde qualquer empresa acaba fazendo jus a uma redução fiscal anual de US\$ 15,000 (quinze mil dólares). ${ }^{27}$ Há também uma espécie da quota de licitação, ou seja, empresas que prestam serviços ao Estado deverão necessariamente contratar pessoas com deficiência. As empresas sob a jurisdição norte-americana contam também com auxílios fiscais que buscam ajudar nos gastos com adaptação do ambiente de trabalho para as PCDs.

Tendo em vista o direito italiano, toma-se como exemplo o sistema de quota-contribuição nos serviços em que não é possível ou ao menos é perigosa a contratação de PCDs. Neste caso, estas atividades serão definidas por Decreto do Ministro do Trabalho que é revisto a cada cinco anos, depois da audição de conferência unificada. ${ }^{28}$ Conforme explica Pastore, nesse sistema, "a obrigação mais alta das empresas é oferecer oportunidades de trabalho. Mas quando isso é (total ou parcialmente) impossível, essas empresas ficam obrigadas a recolher uma certa importância para uma instituição específica, como compensação à parcela de cota legal não preenchida". ${ }^{29}$ Salienta Pastore que tal sistema parte do princípio de que a sociedade e as empresas "têm uma responsabilidade inalienável de criar condições favoráveis para os cidadãos que, por nascença, doença ou acidentes, têm limitações para construir suas vidas com base no trabalho". ${ }^{30}$

No direito espanhol, tem-se algo inusitado: uma cota dentro de outra cota, de forma que esta incide tanto na condição de pessoa com necessidades especiais, quanto no gênero do empregado, visto que a Espanha possui uma política de incentivos fiscais para a contratação de

\footnotetext{
${ }^{27}$ LORENTZ, Luitiana Nacur. A norma da igualdade e o trabalho das pessoas com deficiência. 2. ed. São Paulo: LTr, 2016, p. 361.

${ }^{28}$ LORENTZ, Luitiana Nacur. A norma da igualdade e o trabalho das pessoas com deficiência. 2. ed. São Paulo: LTr, 2016, p. 364.

29 PASTORE, José. Oportunidades de trabalho para portadores de deficiência. São Paulo: Editora LTr, 2000.p. 186-187.

30 PASTORE, José. Oportunidades de trabalho para portadores de deficiência. São Paulo: Editora LTr, 2000.p. 186.
} 
mulheres que apresentam alguma deficiência. Há também a quota-contribuição que, de maneira inovadora, não é revertida a um fundo governamental de ajuda a estes cidadãos, mas sim diretamente às associações de pessoas com deficiência ${ }^{31}$.

É fato que estas medidas alternativas deverão ser aplicadas apenas quando não houver efetivação das normas do ordenamento jurídico nacional e internacional. A quota-contribuição oferecida pelo direito espanhol, por exemplo, deve ser tomada quando por algum motivo não se conseguirem atender às ofertas de emprego e quando não houver pessoas com deficiência interessadas nas vagas disponíveis.

\section{CONCLUSÃO}

A palavra-chave implícita e que permeia as ideias centrais deste artigo é a sensibilidade, visto que todo o desejo em se valorizar a diversidade humana no ambiente de trabalho está fundado na ideia de direitos humanos, em que todos merecem ter respeitados os seus direitos de cidadania simplesmente por serem humanos.

Observa-se que o ordenamento jurídico brasileiro e o internacional estão bem avançados no que tange às normas de inclusão das pessoas com deficiência, no entanto com base nas decisões analisadas, vê-se que o descumprimento das normas se dá geralmente pela falta de preparo dos gestores em como conduzir o processo de inclusão do profissional no ambiente de trabalho, que por esse motivo acabam por dificultar a presença das pessoas com deficiência na empresa: seja desobedecendo a Lei de Cotas quanto à contratação de PCDs, seja contratando a PCD (a fim de não sofrer as sanções que a lei prevê), mas pedindo para que o empregado PCD faça tarefas mínimas, o que acaba por fazê-lo sentir discriminado.

Os obstáculos que impedem a contratação de PCDs são possivelmente vencíveis. Quanto à acessibilidade ao cargo, a lei já prevê o auxílio das cotas, o que se faz necessário é que os dispositivos sejam observados pelos contratantes e que estes se comprometam em contratar o número que a lei exige; bem como devem se comprometer em possibilitar aos empregados com necessidades especiais um espaço acessivo, onde este possa executar suas tarefas com segurança e conforto; o acesso físico ao local de trabalho fazendo uso de transporte coletivo é uma questão de planejamento urbano e é tarefa do executivo de tomar providências quanto a isto.

${ }^{31}$ LORENTZ, Luitiana Nacur. A norma da igualdade e o trabalho das pessoas com deficiência. 2. ed. São Paulo: LTr, 2016, p. 361. 
Os outros obstáculos (violência moral e "falta de pessoas com deficiência") podem ser combatidos fazendo o uso das medidas alternativas discutidas: sobre a violência moral e a discriminação, o Governo Federal juntamente com o Sistema "S" poderiam criar políticas de sensibilização aos empresários, bem como aos demais funcionários, fazendo com que estes acreditem no potencial do empregado PCDs e passem a vê-lo como agente que coopera com o crescimento econômico da empresa, e não como um atraso. Sobre a alegada "falta de pessoas com deficiência" a criação do selo inclusivo incentivaria as empresas a buscarem, com muito mais fôlego, enquadrar-se nas determinações legais.

Neste sentido, pode-se afirmar que o direito ao trabalho da pessoa com deficiência é derivado do conceito de dignidade humana, visto que a pessoa alcançará sua independência econômica de outrem e/ou do próprio Estado (na figura do BPC). Essa independência traz benefícios tanto ao indivíduo, quanto à própria coletividade, visto que será um custo a menos aos cofres públicos e a PCD estará inserida dentre a população economicamente ativa.

Desta forma, é visível que a busca pela inclusão não é um fenômeno de fácil concretização. A reeducação de todas as pessoas do povo faz-se extremamente necessária, para que vejam a inserção das pessoas com deficiência não como um gesto de caridade, mas como um direito inerente a toda pessoa. Agora, o grande desafio é vencer os obstáculos que impossibilitam ou, pelo menos, dificultam a implementação dessas regras, sem embargo de se buscar medidas alternativas que assegurem esses direitos. 0 que não se pode conceber é uma parcela significativa da sociedade ter seus direitos negados pelo simples fato de serem diferentes, afinal, no fim das contas, não existem pessoas iguais.

\section{REFERÊNCIAS}

BAHIA, Melissa Santos. DOS SANTOS, Ernani Marques. Práticas empresariais para a inclusão profissional de pessoas com deficiência. In: CARVALHO-FREITAS, Maria Nivalda de; MARQUES, Antônio Luiz (Organizadores). Trabalho e pessoas com deficiência: Pesquisas, Práticas e Instrumentos de Diagnóstico. Curitiba: Juruá, 2010.

BRASIL. Constituição Federal. Diário Oficial da União. Brasília: Senado Federal, 1988. Disponível em: <http://www.planalto.gov.br/ccivil_03/Constituicao/Constituiçao.htm>. Acesso em: 12 de dez. 2016

BRASIL. Decreto $n^{\circ} 3.298$, de 20 de dezembro de 1999. Regulamenta a Lei no 7.853, de 24 de outubro de 1989, dispõe sobre a Política Nacional para a Integração da Pessoa Portadora de Deficiência, consolida as normas de proteção, e dá outras providências. Diário Oficial da 
República Federativa do Brasil, Brasília, DF, 21. dez. 1999. Disponível em:

<http://www.planalto.gov.br/ccivil_03/decreto/d3298.htm>. Acesso em: 08 mar. 2017.

BRASIL. Decreto ${ }^{\circ}$ 6.949, de 25 de agosto de 2009. Promulga a Convenção Internacional sobre os Direitos das Pessoas com Deficiência e seu Protocolo Facultativo, assinados em Nova York, em 30 de março de 2007. Diário Oficial da República Federativa do Brasil, Brasília, DF, 26. ago. 2009. Disponível em: <http://www.planalto.gov.br/ccivil_03/_ato2007-

2010/2009/decreto/d6949.htm> Acesso em: 08 mar. 2017.

BRASIL. Decreto $n^{\circ} 9.508$, de 24 de setembro de 2018. Reserva às pessoas com deficiência percentual de cargos e de emprego públics ofertados em concursos públicos e em processos seletivos no âmbito da administração públca federal direta e indireta. Diário Oficial da República Federativa do Brasil, Brasília, DF, 25. set. 2018. Disponível em: http://www.planalto.gov.br/ccivil_03/_ato2007-2010/2009/decreto/d9508.htm Acesso em: 27 set. 2018.

BRASIL. Lei $n^{\circ}$ 13.146, de 6 de julho de 2015. Institui a Lei Brasileira de Inclusão da Pessoa com Deficiência (Estatuto da Pessoa com Deficiência). Diário Oficial da República Federativa do Brasil, Brasília, DF, 7. jul. 2015. Disponível em: <http://www.planalto.gov.br/ccivil_03/_ato2015-2018/2015/lei//13146.htm>. Acesso em: 09. mar. 2017.

BRASIL. Lei $n^{\circ} 7.853$, de 24 de outubro de 1989. Dispõe sobre o apoio às pessoas portadoras de deficiência, sua integração social, sobre a Coordenadoria Nacional para Integração da Pessoa Portadora de Deficiência - Corde, institui a tutela jurisdicional de interesses coletivos ou difusos dessas pessoas, disciplina a atuação do Ministério Público, define crimes, e dá outras providências. Diário Oficial da República Federativa do Brasil, Brasília, DF, 25. out. 1989. Disponível em: <http://www.planalto.gov.br/ccivil_03/Leis/L7853.htm> Acesso em: 07 mar. 2018.

BRASIL. Lei $n^{\circ}$ 8.112, de 11 de dezembro de 1990. Dispõe sobre o regime jurídico dos servidores públicos civis da União, das autarquias e das fundações públicas federais. Diário Oficial da República Federativa do Brasil, Brasília, DF, 19. abr. 1991. Disponível em:

<http://www.planalto.gov.br/ccivil_03/Leis/L8112cons.htm>. Acesso em: 07 mar. 2017.

BRASIL. Lei ${ }^{\circ} 8.213$, de 24 de julho de 1991. Dispõe sobre os Planos de Benefícios da Previdência Social e dá outras providências. Diário Oficial da República Federativa do Brasil, Brasília, DF, 25. jul. 1991, republicado 11. abr. 1996 e republicado em 14. ago. 1998. Disponível em: <http://www.planalto.gov.br/Ccivil_03/leis/L8213cons.htm>. Acesso em: 09. mar. 2017.

Brasil. Subsecretaria de Promoção dos Direitos da Pessoa com Deficiência. Comitê de Ajudas Técnicas. Tecnologia Assistiva. Brasília: CORDE, 2009. p. 138.

BRASIL. Tribunal Regional do Trabalho da $3^{\text {a }}$ Região. Acórdão de decisão que deu provimento parcial para condenar a primeira ré ao pagamento de indenização por dano moral. Recurso Ordinário n 00611-2007-021-03-00-7. Ministério Público Do Trabalho. Relator: Luiz Otávio Linhares Renault. 04 de junho de 2008. Disponível em: https://trt3.jusbrasil.com.br/jurisprudencia/129544493/recurso-ordinario-trabalhista-ro-6112007021030070061100-4020075030021. Acesso em: 19 mar. 2017 
CARVALHO-FREITAS, Maria Nivalda de; MARQUES, Antônio Luiz (Organizadores). Trabalho e pessoas com deficiência: Pesquisas, Práticas e Instrumentos de Diagnóstico. Curitiba: Juruá, 2010.

FREIRE VAZ, Cláudia. LIMA, Gabriela Silva de. BEZERRA, Priscila Silva. BRAGA, Maudeth Py. Acessibilidade: da obtenção de um lugar à construção de um espaço. In: CARVALHO-FREITAS, Maria Nivalda de; MARQUES, Antônio Luiz (Organizadores). Trabalho e pessoas com deficiência: Pesquisas, Práticas e Instrumentos de Diagnóstico. Curitiba: Juruá, 2010.

GIL, Marta. Caminhos da Inclusão: a história da formação profissional de pessoas com deficiência no SENAI/SP. São Paulo: SENAI-SP Editora, 2012.

LORENTZ, Luitiana Nacur. A norma da igualdade e o trabalho das pessoas com deficiência. 2 . ed. São Paulo: LTr, 2016.

MANICA, Loni Elisete; CALIMAN, Geraldo. Inclusão das pessoas com deficiência na educação profissional e no trabalho. Jundiaí: Paco Editorial. 2015.

PASTORE, José. Oportunidades de trabalho para portadores de deficiência. São Paulo: Editora LTr, 2000.

Portal Brasil. Disponível em: <www.brasil.gov.br/educacao/2012/02/sistema-s-e-estruturaeducacional-mantida-pela-industria>. Acesso em: 24 abr. 2017.

REBELO, Paulo Antônio de Paiva. A pessoa com deficiência e o trabalho. Rio de Janeiro: Qualitymark, 2008.

SIQUEIRA, Marcus Vinicius Soares; SIMÕES, Jussara Tatiana de Oliveira. Violência Moral e Pessoas com Deficiência: Constrangimentos e Humilhações no Ambiente de Trabalho. Belo Horizonte: V Encontro de Estudos Organizacionais da ANPAD, 2008.

\section{COMO FAZER A REFERÊNCIA DO ARTIGO (ABNT):}

MATOS, Hamanda de Nazaré Freitas; RAIOL, Raimundo Wilson Gama. Pessoas com deficiência e seu direito à inclusão no mercado de trabalho. Revista Eletrônica do Curso de Direito da UFSM, Santa Maria, RS, v. 13, n. 3, p. 927-947, dez. 2018. ISSN 1981-3694. Disponível em: < https://periodicos.ufsm.br/revistadireito/article/view/31468 >. Acesso em: dia mês. ano. doi: http://dx.doi.org/10.5902/1981369431468 . 